\title{
Heritability and Genetic Variance Estimates for Leaf and Stem Resistance to Gummy Stem Blight in Two Cucumber Populations
}

\author{
Paul C. St. Amand ${ }^{1}$ and Todd C. Wehner ${ }^{2}$ \\ Department of Horticultural Science, North Carolina State University, Raleigh, NC 27695-7609
}

AdDitional INDEX words. Cucurbitaceae, Didymella bryoniae, disease resistance, vegetable breeding

\begin{abstract}
Heritability of resistance to gummy stem blight (Didymella bryoniae (Auersw.) Rehm.) was measured in two diverse cucumber (Cucumis sativus L.) populations [North Carolina elite slicer 1 (NCES1) and North Carolina wide base pickle (NCWBP)]. Heritability was estimated using parent-offspring regression and half-sib family analysis in North Carolina field tests during 1991 and 1992. NCES1 is a slicing cucumber population with a narrow genetic base, and NCWBP is a pickling cucumber population with a wide genetic base. Heritability estimates were low to moderate ranging from 0.12 to 0.49 for the gummy stem blight leaf rating and from $\mathbf{- 0 . 0 3}$ to 0.12 for stem rating. Estimates of gain from selection were at least two times larger for selection based on half-sib families than for mass selection for all traits in both populations. Approximately three to five cycles of selection would be required to improve the NCES1 population mean for gummy stem blight leaf resistance by one rating scale unit, and three to four cycles of selection would be required to improve the NCWBP population mean for gummy stem blight leaf resistance by one rating scale unit, based on half-sib family selection. One rating scale unit decrease is equivalent to an $11 \%$ reduction in susceptibility. Gain would be slower if selecting for stem, or leaf and stem resistance. A moderate amount of additive genetic variation exists in both populations for gummy stem blight leaf resistance, but estimates for additive genetic variation for stem resistance indicate little to no additive genetic variation. Development of populations specifically for greater initial resistance and greater additive variance than found in these populations should aid in selection for resistance.
\end{abstract}

Gummy stem blight of cucumber (Cucumis sativus) is caused by the fungus Didymella bryoniae (Auersw.) Rehm., which causes severe defoliation and stem necrosis in the late stages of cucumber production. The incidence and severity of damage due to gummy stem blight on cucumber is second only to root knot nematode (Meloidogyne incognita, Kofoid and White) in North Carolina (St. Amand and Wehner, 1991), an important cucumber producing state. Control of gummy stem blight on watermelon [Citrullus lanatus (Thunb.) Matsum. and Nakai] currently requires three to six applications of fungicide during the first half of the growing season or continuing all season (Keinath, 1995). Crop rotation is also useful for control on watermelon (Keinath, 1996). Similar practices are necessary for optimum control on cucumber.

Although fungicides are available, genetic resistance is usually more effective, less costly, less subject to environmental conditions, and easier for growers to implement. Resistant cultigens (cultivars, plant introductions, and breeding lines) were used by Wehner and St. Amand (1993) to show that resistance was quantitatively inherited. Additional research showed that resistance was due to more than five genes (St. Amand and Wehner, 2000).

Genetic improvement of plants for quantitative traits requires reliable estimates of heritability in order to plan an efficient breeding program (Dudley and Moll, 1969). Wyszogrodzka et al. (1986) reported the realized heritability for foliar resistance in

Received for publication 26 May 1998. Accepted for publication 23 Aug. 2000. Research was supported in part by a grant from the North Carolina Pickle Producers Assoc., Mount Olive, NC 28365. We gratefully acknowledge technical assistance of R. R. Horton, Jr. The cost of publishing this paper was defrayed in part by the payment of page charges. Under postal regulations, this paper therefore must be hereby marked advertisement solely to indicate this fact.

${ }^{1}$ Former graduate research assistant. Currently assistant professor, Department of Agronomy, Kansas State University, Manhattan KS 66506.

${ }^{2}$ Professor; to whom reprint requests should be addressed. one cycle of mass selection within the open pollinated slicing cucumber 'Homegreen \#2' was 0.14 to 0.35 . However, we know of no other estimates of heritability or genetic variance of resistance to gummy stem blight in cucumber populations.

The objective of this research was to estimate the heritability of leaf and stem resistance to gummy stem blight in two diverse cucumber populations. Other objectives were to estimate additive and environmental variation, to determine the suitability of the examined populations for improvement of resistance to gummy stem blight, and to predict genetic gain from selection in these populations.

\section{Materials and Methods}

Populations TESTED. Two cucumber populations were used in this study: the North Carolina elite slicer 1 (NCES1) and the North Carolina wide base pickle (NCWBP). The NCES1 population was formed by intercrossing eight elite slicing type cultigens (Wehner, 1998). Because of the small number of parents used, that population was expected to contain less genetic variability than NCWBP, which was formed by intercrossing 1063 cultigens and selecting for pickle types (Wehner, 1997). Both populations were improved through recurrent selection cycles (seven for NCES1 and eight for NCWBP) for fruit yield (total, marketable, and early) and fruit quality (type, color, and shape) prior to this study. The parent populations used in this study were each formed by sampling five seeds from approximately 400 halfsib families and bulking the seeds.

INOCULUM PREPARATION AND APPLICATION. Conidia were produced as reported previously (St. Amand and Wehner, 1995b, 2000). Only one locally collected, single spore isolate of $D$. bryoniae (DB-H-23) was used for inoculation because cultigen by isolate interactions are not known (St. Amand and Wehner, 1995a).

Plants were sprayed with conidia nearly to runoff at the vine 
tipover stage (four to six true leaves) using a backpack sprayer (Solo, Sindelfingen, Germany) at 103 to $138 \mathrm{kPa}$ (15 to $20 \mathrm{psi}$ ) 2 weeks after planting. A second inoculation was applied 3 weeks after planting due to poor disease development following the initial inoculation. Both inoculations occurred within $2 \mathrm{~h}$ after sunrise, before guttation exudates had dried from the leaves. Overhead irrigation was used ( 25 to $38 \mathrm{~mm}$ ) $3 \mathrm{~d}$ after inoculation to spread the inoculum and encourage uniform disease development. Susceptible 'Wisconsin SMR 18' was planted in every fourth row of the field test to enhance the uniformity of disease spread.

EXPERIMENTAL DESIGN AND DATA ANALYSIS. Parent populations for the parent-offspring regression study were planted at the Horticultural Crops Research Station, Clayton, N.C., on 15 May 1991. Parents were individual $S_{0}$ plants in unreplicated, singlehill, spaced plots. Each population was separated from other cucumber fields a minimum of $500 \mathrm{~m}$ to reduce outcrossing. Only naturally occurring pollinators were used. Seeds were harvested from one mature fruit per parent in each population to form 144 half-sib families.

Offspring populations, used for the parent-offspring regression study and for half-sib analysis, were planted in Spring (8 June) and Fall (27 July) 1992 at the Horticultural Crops Research Station, Clinton, N.C. Seasons have been shown to contribute greatly to environmental variation for yield in cucumber (Wehner, 1987) and disease reactions can vary greatly between seasons (Wehner and Horton, 1992). Parents were rated in 1991 and offspring in 1992, ensuring that no environmental covariance existed between parents and offspring. Such a covariance would constitute a major violation of the assumptions necessary for a parent-offspring regression (Nyquist, 1991). Plots were $3 \mathrm{~m}$ long and were planted on raised, shaped beds $1.5 \mathrm{~m}$ apart (center to center) separated at each end by $3 \mathrm{~m}$ alleys. Guard rows of susceptible 'Wisconsin SMR 18' surrounded offspring tests. Standard cultural practices were used for crop production in parent and offspring plantings (Hughes et al., 1983).

Offspring plots were half-sib families, with five plants per plot. Families (144) were divided into nine sets of 16 families each. Families were randomized within replications (two), and replications within sets, for each environment and population. Plant spacing between rows $(1.5 \mathrm{~m})$ was the same for parents and offspring; but within-row spacing was greater for parents $(60 \mathrm{~cm})$ compared to within-plot spacing for offspring $(30 \mathrm{~cm})$. In all plantings, individual plants were rated 3 weeks after inoculation for foliar and stem lesions using a linear 0 to 9 scale $(0=$ no symptoms and $9=100 \%$ necrosis) indicating the average degree of necrosis on all leaves, or the average degree of necrosis, cankers, and exudates on all stems. Each increase of the scale is equal to approximately $11.1 \%$ more necrotic area. Each parent plant was rated individually and the first three plants of each offspring plot were rated individually for a total of 12 offspring per half-sib family ( 3 plants $\mathrm{x} 2$ replications $\mathrm{x} 2$ environments).

A simple nonweighted average based on the mean leaf and stem rating for each plant was calculated and used as a third trait to determine if gain would increase by the use of this simple index. The parent-offspring regression coefficient $\left(b_{\mathrm{OP}}\right)$ was calculated using PROC REG of SAS (SAS Inst., Inc., N.C.). Analysis of variance (ANOVA) was performed for leaf, stem, and average ratings for the half-sib analysis of offspring families using PROC GLM of SAS. Variance components for the statistical design were calculated using the TYPE = MIVQUE0 option in PROC VARCOMP of SAS. This method of variance compo- nent calculation does not set negative variance components equal to zero, a practice warned against by Dudley and Moll (1969). Phenotypic correlations were calculated using PROC CORR of SAS.

The estimate of heritability by parent-offspring regression can be influenced greatly by environments. Environmental variance can cause a greater or lesser range of trait expression in the offspring relative to the parents (Nyquist, 1991). In addition to calculating the regression coefficients using actual ratings for each trait, regression coefficients were also calculated using standardized data as suggested by Frey and Horner (1957) to adjust for a possible bias due to differing ranges of trait expression over environments. For leaf and stem ratings, data on individual plants were standardized to a mean of 4.5 and a SD of 1 using PROC STANDARD of SAS.

\section{Results}

Parent-offspring regression. The NCWBP population was more susceptible than the NCES1 population for leaf, stem, and mean (combined) ratings (Table 1). Population means ranged from 5.6 to 7.2 for leaf ratings over environments and from 4.1 to 5.2 for stem ratings. Average ratings were intermediate. For all traits, resistance was greater in the spring for the NCWBP population, but was greater in the fall for the NCES1 population.

Heritability estimates in standardized units did not differ appreciably from actual heritability estimates for any trait or population (data not presented). Estimates of additive genetic variation were $19 \%$ to $100 \%$ smaller in the NCES1 population compared with the NCWBP population when pooled over environments. Heritability estimates ranged from 0.12 to 0.49 for leaf rating, from -0.03 to 0.12 for stem rating, and from 0.05 to 0.28 for average rating when pooled over populations and environments. Negative heritability and variance estimates can be assumed to be zero (Robinson et al., 1955), but should be reported (Dudley and Moll, 1969). Heritability estimates based on pooled offspring environments were intermediate to those based on separate environments for all three traits and both populations.

Based on estimates from the parent-offspring regression, genetic gain from selection was estimated for phenotypic recurrent selection $(10 \%)$ after anthesis (Table 1). Estimates of gain were usually greater in the NCWBP population and ranged from 0.07 to 0.37 rating scale units when averaged over populations.

HALF-SIB FAMILY ANALYSIS. Heritability, genetic gain, and variances for half-sib analysis in two environments are presented in Table 2. Results from the ANOVA show significant differences $(P=0.0001)$ among families for leaf, stem, and average ratings in both populations. Environments were different $(P=$ 0.001 ) for all traits in both populations, except for stem rating in the NCWBP population. Environment by family interaction was significant $(P=0.0001)$ for all traits in both populations.

Estimates of additive genetic variance were similar between populations for leaf $(0.50)$ and average $(0.10)$ ratings, but additive genetic variance for stem rating $(0.27)$ in the NCES1 population was considerably larger than additive genetic variance for stem rating $(-0.16)$ in the NCWBP population. Environmental variance was usually the smallest component of variance; yet, environment by additive interaction was one of the largest components of variance in both populations. Within-plot error variance was also relatively large in both populations.

Estimates of narrow-sense heritabilities for use in selecting among half-sib families and among individuals (mass selection), 
Table 1. Means and estimates of heritability, additive variance, and gain from selection for leaf and stem resistance to gummy stem blight in two cucumber populations as determined by parent-offspring regression. Resistance was rated visually using a 0 (no symptoms) to 9 (100\% necrosis) scale. Parents were tested in the Spring 1991 at Clayton, N.C. and offspring were tested in Spring and Fall of 1992 Clinton, N.C.

\begin{tabular}{|c|c|c|c|c|c|c|}
\hline \multirow[b]{2}{*}{ Statistic $^{\mathrm{y}}$} & \multicolumn{3}{|c|}{ NCES1 Population ${ }^{z}$} & \multicolumn{3}{|c|}{ NCWBP Population $^{z}$} \\
\hline & Spring & Fall & Pooled $^{\mathrm{x}}$ & Spring & Fall & Pooled $^{x}$ \\
\hline \multicolumn{7}{|c|}{ Leaf rating } \\
\hline M & 5.95 & 5.64 & 5.79 & 6.67 & 7.17 & 6.91 \\
\hline $\mathrm{X}_{\mathrm{H}}$ & 8.50 & 8.17 & 7.67 & 8.50 & 9.00 & 8.42 \\
\hline$X_{L}$ & 2.50 & 2.75 & 3.20 & 3.00 & 4.33 & 4.58 \\
\hline$h^{2}$ & 0.15 & 0.12 & 0.14 & 0.14 & 0.49 & 0.32 \\
\hline$\sigma_{A}^{2}$ & 0.47 & 0.37 & 0.44 & 0.23 & 0.82 & 0.54 \\
\hline GS & 0.23 & 0.18 & 0.22 & 0.16 & 0.56 & 0.37 \\
\hline \multicolumn{7}{|c|}{ Stem rating } \\
\hline M & 4.61 & 4.06 & 4.33 & 5.00 & 5.15 & 5.07 \\
\hline $\mathrm{X}_{\mathrm{H}}$ & 7.50 & 7.50 & 7.00 & 7.50 & 8.33 & 6.83 \\
\hline$X_{L}$ & 3.00 & 1.33 & 2.33 & 3.50 & 2.50 & 3.33 \\
\hline $\mathrm{h}^{2}$ & -0.01 & -0.03 & -0.02 & -0.01 & 0.12 & 0.06 \\
\hline$\sigma_{\mathrm{A}}^{2}$ & -0.07 & -0.19 & -0.13 & -0.03 & 0.48 & 0.22 \\
\hline GS & 0.00 & 0.00 & 0.00 & 0.00 & 0.21 & 0.10 \\
\hline \multicolumn{7}{|c|}{ Mean (leaf and stem) rating } \\
\hline M & 5.28 & 4.85 & 5.06 & 5.84 & 6.16 & 5.99 \\
\hline $\mathrm{X}_{\mathrm{H}}$ & 7.50 & 7.50 & 7.00 & 7.83 & 8.50 & 7.33 \\
\hline$X_{L}$ & 3.33 & 2.12 & 3.05 & 3.50 & 3.50 & 4.12 \\
\hline$h^{2}$ & 0.05 & 0.05 & 0.05 & 0.05 & 0.28 & 0.17 \\
\hline$\sigma_{\mathrm{A}}^{2}$ & 0.20 & 0.21 & 0.21 & 0.12 & 0.66 & 0.39 \\
\hline GS & 0.09 & 0.09 & 0.09 & 0.07 & 0.37 & 0.22 \\
\hline
\end{tabular}

${ }^{\mathrm{z}}$ Elite slicer and wide-based pickle populations.

yStatistic: $M=$ mean, $X_{H}=$ most resistant family, $X_{L}=$ most susceptible family, $h^{2}=$ narrow-sense heritability, $\sigma^{2}{ }_{A}=$ additive genetic variance, GS $=$ gain based on mass selection $(10 \%)$ after anthesis $\left[(1.75)(1 / 2)\left(\sigma_{\mathrm{A}}^{2}\right) / \sigma_{\mathrm{P}}\right]$.

${ }^{\mathrm{x}}$ Spring and fall data combined.

ranged from -0.32 to 0.23 among populations (Table 2). Estimates of gain from selection were at least two times larger for selection based on half-sib families compared to mass selection in both populations for all traits. Estimated gain for leaf resistance was larger than that for stem or average resistance in both populations.

Correlations among traits. Correlations between leaf and stem ratings, using data from the half-sib analysis, were low to negative within both populations (Table 3 ). Genetic correlations were usually lower than phenotypic correlations. Correlations between leaf and average rating or between stem and average rating were moderate to high.
Phenotypic correlations between leaf and stem ratings based on individual offspring plants were significantly larger in the fall $(r=0.28$ for NCES1 and $r=0.41$ for NCWBP) compared with spring ratings ( $r=0.11$ for NCES1 and $r=0.22$ for NCWBP). Phenotypic correlations between leaf and stem ratings for parent plants $(r=0.71$ for NCES1 and $r=0.74$ for NCWBP) were significantly larger than those for offspring.

\section{Discussion}

Resistance to gummy stem blight is usually greater in the spring (Wehner and Horton, 1992), as was true in this study for

Table 2. Means and estimates of heritability, variance, and gain from selection for leaf, stem, and mean (combined) resistance to gummy stem blight in two cucumber populations tested by half-sib analysis in two environments. Resistance was rated visually using a 0 (no symptoms) to 9 (100\% necrosis) scale.

\begin{tabular}{|c|c|c|c|c|c|c|}
\hline \multirow[b]{2}{*}{ Statistic $^{y}$} & \multicolumn{3}{|c|}{ NCES1 population ${ }^{2}$} & \multicolumn{3}{|c|}{ NCWBP population $^{\mathrm{z}}$} \\
\hline & Leaf & Stem & Mean & Leaf & Stem & Mean \\
\hline$\overline{\mathrm{M}}$ & 5.80 & 4.33 & 5.06 & 6.94 & 5.08 & 6.01 \\
\hline$\sigma_{\mathrm{E}}^{2}$ & 0.04 & 0.15 & 0.09 & 0.11 & 0.00 & 0.04 \\
\hline$\sigma^{2}$ & 0.50 & 0.27 & 0.10 & 0.55 & $-0.16^{\mathrm{x}}$ & 0.11 \\
\hline$h^{2}{ }_{N(H S)}$ & 0.18 & 0.11 & 0.06 & 0.23 & -0.32 & 0.07 \\
\hline$h^{2}{ }_{N(\mathrm{HS})}$ & 0.17 & 0.09 & 0.06 & 0.22 & -0.05 & 0.06 \\
\hline $\mathrm{G}_{\mathrm{S}(\mathrm{HS})}^{\mathrm{N}(\mathrm{s})}$ & 0.32 & 0.20 & 0.11 & 0.41 & 0.00 & 0.13 \\
\hline $\mathrm{G}_{\mathrm{S}(\mathrm{I})}^{\mathrm{S}(\mathrm{HS})}$ & 0.15 & 0.08 & 0.05 & 0.19 & 0.00 & 0.05 \\
\hline
\end{tabular}

${ }^{\mathrm{z}}$ Elite slicer and wide-based pickle populations.

${ }^{\mathrm{y}}$ Statistic: $\mathrm{M}=$ population mean, $\sigma_{\mathrm{E}}^{2}=$ environmental variance, $\sigma_{\mathrm{A}}^{2}=$ additive variance, $\mathrm{h}_{\mathrm{N}(\mathrm{HS})}^{2}=$ narrow-sense heritability of half-sibs, $\mathrm{h}^{2}{ }_{\mathrm{N}(\mathrm{I})}=$ narrow-sense heritability of individuals, $\mathrm{G}_{\mathrm{S}(\mathrm{HS})}=$ Gain (based on half-sib family selection $(10 \%)$ by recombining remnant seed of selected families), $\mathrm{G}_{\mathrm{S}(\mathrm{I})}=$ Gain (based on mass selection (10\%) after anthesis).

${ }^{x}$ Negative variances and heritabilities used in calculations and reported but assumed to be zero. 
Table 3. Genetic (above diagonal) ${ }^{\mathrm{z}}$ and phenotypic (below diagonal) ${ }^{\mathrm{y}}$ correlations between leaf, stem, and mean (combined) resistance to gummy stem blight in two cucumber populations (NCES1 and NCWBP) tested by half-sib analysis in two environments.

\begin{tabular}{|c|c|c|c|c|c|c|}
\hline \multirow[b]{2}{*}{ Trait } & \multicolumn{3}{|c|}{ NCES1 population ${ }^{\mathrm{x}}$} & \multicolumn{3}{|c|}{ NCWBP population } \\
\hline & Leaf & Stem & Mean & Leaf & Stem & Mean \\
\hline$\overline{\text { Leaf }}$ & --- & -0.35 & 0.70 & --- & $\mathrm{NC}^{\mathrm{W}}$ & 1.16 \\
\hline Stem & 0.27 & --- & 0.43 & 0.37 & --- & $\mathrm{NC}$ \\
\hline Average & 0.81 & 0.78 & --- & 0.84 & 0.81 & --- \\
\hline
\end{tabular}

${ }^{\overline{\mathrm{z}} \mathrm{Genetic} \mathrm{correlations} \mathrm{calculated} \mathrm{as} \mathrm{r}_{\mathrm{Gij}}=\sigma_{\mathrm{Gij}} /\left(\sigma_{\mathrm{Gi}}^{2} \times \sigma_{\mathrm{Gj}}^{2}\right)^{0.5} \text {; where the genetic covariance component }\left(\sigma_{\mathrm{Gij}}\right) \text { was estimated as }\left(\mathrm{MS}_{\mathrm{Fij}}-\mathrm{MS}_{\mathrm{E} \times \mathrm{Fij}}\right) /}$ nre and the genetic variance components $\left(\sigma_{\mathrm{Gi}}^{2}\right.$ and $\left.\sigma_{\mathrm{Gj}}^{2}\right)$ were estimated as $\left(\mathrm{MS}_{\mathrm{Fi}}-\mathrm{MS}_{\mathrm{E} \times \mathrm{Fi}}\right) / \mathrm{nre}$ and $\left(\mathrm{MS}_{\mathrm{Fj}}-\mathrm{MS}_{\mathrm{E} \times \mathrm{Fj}}\right) / \mathrm{nre}$, where nre are the number of plants per plot, replications, and environments, respectively.

yPhenotypic correlations calculated as $\mathrm{r}_{\mathrm{Pij}}=\sigma_{\mathrm{Pij}} /\left(\sigma_{\mathrm{Pi}}^{2} \times \sigma_{\mathrm{Pj}}^{2}\right)^{0.5}$; where the phenotypic covariance component $\left(\sigma_{\mathrm{Pij}}\right)$ was estimated as MS $\mathrm{Fij} / \mathrm{nre}$ and the phenotypic variance components $\left(\sigma_{\mathrm{Pi}}^{2}\right.$ and $\left.\sigma_{\mathrm{Pj}}^{2}\right)$ were estimated as $\mathrm{MS}_{\mathrm{Fi}} / \mathrm{nre}$ and $\mathrm{MS}_{\mathrm{Fj}} / \mathrm{nre}$.

${ }^{x}$ Elite slicer and wide-based pickle populations.

${ }^{\mathrm{w}} \mathrm{NC}$, genetic correlation not calculable due to negative genetic variance for stem.

the NCWBP population. It was therefore surprising to find that resistance was greater in the fall for the NCES1 population. Significant differences among families existed for all resistance traits in both populations. Environments and environment by family interactions were usually significant for all traits in both populations.

Heritability estimates were low to moderate (Table 1), and were similar to realized heritabilities for leaf resistance reported by Wyszogrodzka et al. (1986). The range of values for gummy stem blight ratings, and the estimates of phenotypic variance were usually similar for parents and offspring, and may explain why standardized heritability estimates were not appreciably different from actual heritability estimates. Resistance in the NCWBP population was influenced by the environment to a greater degree than was the NCES1 population, as indicated by the greater difference in heritabilities from spring to fall for the NCWBP population in the parent-offspring regression. Estimates of narrow-sense heritabilities for use in selecting among individuals were usually similar to those calculated by parent-offspring regression for pooled environments.

Estimates of gain from selection were at least two times larger for selection based on half-sib families compared to mass selection for both populations and all traits. Estimates of gain can be used to predict selection progress if it is assumed that genetic and phenotypic variances remain constant over many cycles of selection (an unlikely but necessary assumption). In that case, three to five cycles of selection would be required to decrease the NCES1 population mean for leaf rating by one rating scale unit, and three to four cycles of selection would be required to decrease the NCWBP population mean for leaf rating by one rating scale unit, based on half-sib family selection. One rating scale unit decrease is equivalent to an $11 \%$ reduction in susceptibility. Gain would be even slower using mass selection because it does not control environmental variation as well as other methods. Gain while selecting for stem or average resistance would be slower than selection for leaf resistance because of the lower heritability of stem resistance. Gain in these populations would therefore be moderate to slow; however, these populations were not developed specifically for disease resistance and have been selected mainly for fruit yield, quality, and type for seven to eight cycles.

A moderate amount of additive genetic variance exists in both populations for gummy stem blight leaf resistance, but estimates for additive genetic variance for stem resistance indicated little to no additive genetic variance. Estimates of additive variance for leaf resistance were consistent between the methods used to estimate heritability and genetic variance (Tables 1 and 2).
However, estimates of additive variance for stem resistance varied between methods. Parent-offspring regression indicated moderate additive variance for stem rating in the NCWBP population, but zero variance for the NCES1 population. The rankings of additive variance were reversed when estimated using half-sib analysis. The higher estimate in the NCWBP population by parent-offspring regression was due to a large additive variance during the fall.

As expected, given the narrow genetic background of NCES1 and the very broad genetic makeup of the NCWBP population, estimates of additive genetic variance were usually smaller in the NCES1 population. However, when estimated using half-sib analysis, additive variance for stem resistance was larger in NCES1, compared with the NCWBP population. Gain from selection for leaf resistance to gummy stem blight in both populations is predicted to be moderate, but gain for stem resistance, or for average leaf and stem resistance, will likely be slow.

It would be desirable to improve populations for both leaf and stem resistance simultaneously. There was no advantage in using an average rating or index compared with either leaf or stem ratings alone. Gain and heritabilities for the average were intermediate between leaf and stem ratings. Also, phenotypic correlations between leaf and stem ratings were low $(r=0.27$ and 0.37$)$, and the genetic correlation between leaf and stem ratings was negative for NCES1 and not calculable for the NCWBP population. Low correlations between traits could indicate that multiple genes conferring leaf and stem resistance are, at least to some degree, independent, and have not been subjected to simultaneous selection pressure, as was the case for these populations prior to this study. Pleiotropic effects, in which a single gene affects both traits, also impact correlations between traits. There is no direct evidence however, that a given gene would both increase leaf resistance and decrease stem resistance, or vice versa, in this pathosystem. Negative correlations for the two resistance traits in NCES1 indicate that gain for both traits selected simultaneously may be slow. Development of populations specifically for greater initial resistance and greater additive variance than found in these populations should aid in selection for resistance. Populations with increased resistance to gummy stem blight could be formed by intercrossing the more resistant cultigens reported by Wyszogrodzka et al. (1986) and Wehner and St. Amand (1993). Breeding methodologies that control environmental variation well, such as the use of family selection or progeny testing, will improve the rate of gain for these traits because of the relatively large environmental variance associated with both leaf and stem ratings of resistance to gummy stem blight. 


\section{Literature Cited}

Dudley, J.W. and R.H. Moll. 1969. Interpretation and use of estimates of heritability and genetic variances in plant breeding. Crop Sci. 9:257262.

Frey, K.J. and T. Horner. 1957. Heritability in standard units. Agron. J. 49:59-62.

Hughes, G.R., C.W. Averre, and K.A. Sorensen. 1983. Growing pickling cucumbers in North Carolina. N.C. Agr. Ext. Serv. AG-315.

Keinath, A.P. 1995. Fungicide timing for optimum management of gummy stem blight epidemics on watermelon. Plant Dis. 79:354-358.

Keinath, A.P. 1996. Soil amendment with cabbage residue and crop rotation to reduce gummy stem blight and increase growth and yield of watermelon. Plant Dis. 80:564-570.

Nyquist, W.E. 1991. Estimation of heritability and prediction of selection response in plant populations. Critical Rev. Plant Sci. 10:235-322.

Robinson, D.C., R.E. Comstock, and P.H. Harvey. 1955. Genetic variances in open pollinated corn. Genetics 40:45-60.

St. Amand, P.C. and T.C. Wehner. 1991. Crop loss to 14 diseases of cucumber in North Carolina from 1983 to 1988. Cucurbit Genet. Coop. Rpt. 14:15-17.

St. Amand, P.C. and T.C. Wehner. 1995a. Eight isolates of Didymella bryoniae from geographically diverse areas exhibit variation in viru- lence but no isolate by cultivar interaction on Cucumis sativus. Plant Dis. 79:1136-1139.

St. Amand, P.C. and T.C. Wehner. 1995b. Greenhouse, detached-leaf, and field testing methods to determine cucumber resistance to gummy stem blight. J. Amer. Soc. Hort. Sci. 120:673-680.

St. Amand, P.C. and T.C. Wehner. 2000. Generation means analysis of leaf and stem resistance to gummy stem blight in cucumber. J. Amer. Soc. Hort. Sci. 124: (In press).

Wehner, T.C. 1987. Genotype-environment interaction for cucumber yield in 23 North Carolina environments. Cucurbit Genet. Coop. Rpt. 10:25-26.

Wehner, T.C. 1997. Three pickling cucumber populations: NCWBP, NCMBP, and NCEP1. HortScience 32:941-944.

Wehner, T.C. 1998. Three slicing cucumber populations: NCWBS, NCMBS, and NCES1. HortScience 33:168-170.

Wehner, T.C. and R. R. Horton. 1992. NCSU cucumber breeding report. Dept. of Hort. Sci., North Carolina State Univ., Raleigh.

Wehner, T.C. and P.C. St. Amand. 1993. Field tests for cucumber resistance to gummy stem blight in North Carolina. HortScience 28:327-329.

Wyszogrodzka, A.J., P.H. Williams, and C.E. Peterson. 1986. Search for resistance to gummy stem blight (Didymella bryoniae) in cucumber (Cucumis sativus L.). Euphytica 35:603-613. 